\title{
REVIEW
}

\section{Tropical chronic pancreatitis}

\author{
K K Barman, G Premalatha, V Mohan
}

Tropical chronic pancreatitis (TCP) is a juvenile form of chronic calcific non-alcoholic pancreatitis, seen almost exclusively in the developing countries of the tropical world. The classical triad of TCP consists of abdominal pain, steatorrhoea, and diabetes. When diabetes is present, the condition is called fibrocalculous pancreatic diabetes (FCPD) which is thus a later stage of TCP. Some of the distinctive features of TCP are younger age at onset, presence of large intraductal calculi, more aggressive course of the disease, and a high susceptibility to pancreatic cancer. Pancreatic calculi are the hallmark for the diagnosis of TCP and in non-calcific cases ductal dilation on endoscopic retrograde cholangiopancreatography, computed tomography, or ultrasound helps to identify the disease. Diabetes is usually quite severe and of the insulin requiring type, but ketosis is rare. Microvascular complications of diabetes occur as frequently as in type 2 diabetes but macrovascular complications are uncommon. Pancreatic enzyme supplements are used for relief of abdominal pain and reducing the symptoms related to steatorrhoea. Early diagnosis and better control of the endocrine and exocrine dysfunction could help to ensure better survival and improve the prognosis and quality of life of TCP patients.

See end of article for authors' affiliations

Correspondence to:

Professor V Mohan, M V

Diabetes Specialities

Centre and Madras

Diabetes Research

Foundation 6B, Conran

Smith Road,

Gopalapuram, Chennai

600 086, India;

mvdsc@vsnl.com

Submitted 24 April 2003 Accepted 12 May 2003

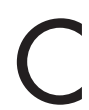
hronic pancreatitis is a condition characterised by irreversible destruction and fibrosis of the exocrine parenchyma, leading to exocrine pancreatic insufficiency and progressive endocrine failure leading to diabetes. Alcoholic chronic pancreatitis is the commonest type of chronic pancreatitis seen in the western world, while in the tropics there is a distinct nonalcoholic type of chronic pancreatitis of uncertain aetiology, which is far more common. Several names have been proposed for this type of chronic pancreatitis including tropical chronic pancreatitis (TCP), tropical calcific pancreatitis, juvenile pancreatitis syndrome, Afro-Asian pancreatitis, and fibrocalculous pancreatic diabetes. We prefer to use tropical calcific pancreatitis to describe the early prediabetic stage of the disease and the term fibrocalculous pancreatic diabetes (FCPD), a term introduced by the World Health Organisation (WHO) Study Group report on diabetes, ${ }^{1}$ to denote the later, diabetic stage of the syndrome (fig 1). However both terms are often used interchangeably as they essentially refer to the same disease.

\section{DEFINITION}

TCP can be defined as a juvenile form of chronic calcific non-alcoholic pancreatitis prevalent almost exclusively in the developing countries of the tropical world. Some of its distinctive features are younger age at onset, presence of large intraductal calculi, an accelerated course of the disease leading the end points of diabetes and/or steatorrhoea, and a high susceptibility to pancreatic cancer. ${ }^{2-5}$

The differences between TCP and alcoholic chronic pancreatitis are summarised in table $1 .{ }^{6}$

\section{EPIDEMIOLOGY}

In 1959, Zuidema first reported a series of patients with pancreatic calculi and clinical features of undernutrition occurring in the lower socioeconomic strata of society. ${ }^{7}$ Since then, many reports have been published establishing TCP as a distinct form of chronic pancreatitis that is present in many developing countries in the tropics. ${ }^{8-11}$

The first case of pancreatic calculi from India was reported by Kini in $1937^{10}$ and this was followed by reports of pancreatic calculi observed at postmortem from Vellore in southern India. ${ }^{11}$ Reports from several tropical parts of the world ${ }^{11}$ including Nigeria, ${ }^{12}$ Uganda, ${ }^{13}$ other parts of Africa, ${ }^{14}$ Brazil, ${ }^{15}$ Thailand, ${ }^{16}$ Bangladesh, ${ }^{17}$ and Sri Lanka ${ }^{18}$ have subsequently confirmed the existence of TCP. However, it was after Geevarghese, one of the pioneers in the field, documented one of the largest series in the world from Kerala state in Southern India that TCP attracted international attention. ${ }^{8}{ }^{19}$ Large series of TCP patients have also been reported by a number of workers from various states in India. ${ }^{20-32}$

At the M V Diabetes Specialities Centre, Chennai (formerly Madras), a large referral centre for diabetes in south India, about 50 patients with FCPD are registered annually, which constitutes about $1 \%$ of all diabetic patients seen at the centre. ${ }^{2}$ Unfortunately most of the available data are clinic based and hence subject to referral bias. There is very little information on the prevalence of TCP in the population. One survey done in Kerala reported a prevalence of 125/100 000 population. ${ }^{33}$ However this was done in an area that is endemic for TCP and the frequency is probably much lower in other parts of India. In a recent study from

Abbreviations: BT-PABA, N-benzoyl L-tyrosyl-paraaminobenzoic acid; ERCP, endoscopic retrograde cholangiopancreatography; FCPD, fibrocalculous pancreatic diabetes; NEFA, non-esterified fatty acid; TCP, tropical chronic pancreatitis; WHO, World Health Organisation 


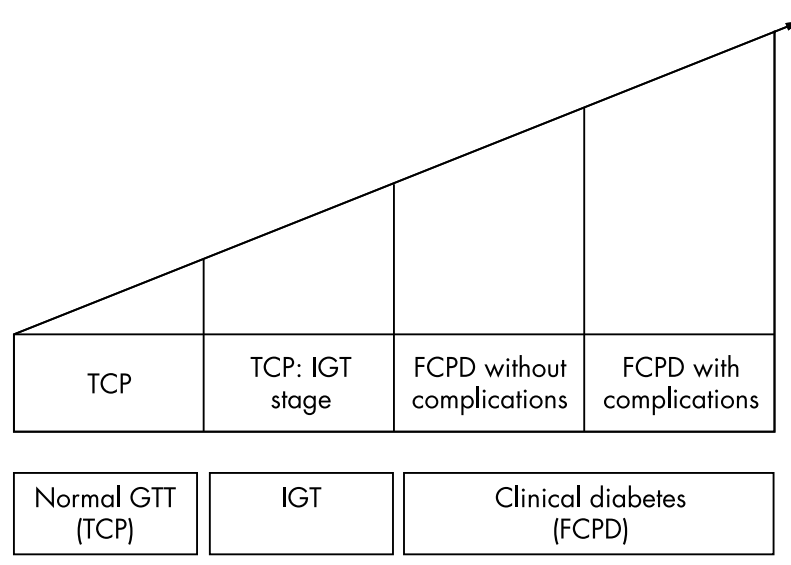

Figure 1 Natural history of tropical chronic pancreatitis (TCP); FCPD fibrocalculous pancreatic diabetes; GT, glucose tolerance test; IGT, impaired glucose tolerance.

Japan, prevalence of chronic pancreatitis was reported to be $45.4 / 100000$ population, ${ }^{34}$ which is higher than in western countries where it is reported to be approximately 10-15/ 100000 population with an annual incidence of 3.5-4/ 100000 population..$^{35-37}$

\section{CLINICAL PRESENTATION}

TCP patients present with several distinct clinical features. Earlier reports suggested that patients were poor, extremely emaciated, young (over $90 \%$ are below 40 years of age at onset), and emphasised the presence of protein calorie malnutrition, bilateral parotid enlargement, distended abdomen, and sometimes with a cyanotic hue of the lips. ${ }^{89}$ However, recent reports suggest a change in the clinical presentation that may be attributed to improved nutritional status. ${ }^{2124} 28$ We found that while the majority of patients were lean, severe malnutrition was uncommon; many patients were of ideal body weight ${ }^{28}$ and an occasional patient even obese. ${ }^{38}$ Most of the patients are aged 10-30 years when the diagnosis is made, but onset of TCP in infancy, ${ }^{39}$ childhood, ${ }^{40}$ and the elderly ${ }^{41}$ is not uncommon. The clinical picture of TCP consists of a triad of:

- Abdominal pain.

- Maldigestion leading to steatorrhoea.

- Diabetes.

Table 1 Differences between tropical chronic pancreatitis and alcoholic chronic pancreatitis

\begin{tabular}{|c|c|c|}
\hline & $\begin{array}{l}\text { Tropical chronic } \\
\text { pancreatitis }\end{array}$ & $\begin{array}{l}\text { Alcoholic chronic } \\
\text { pancreatitis }\end{array}$ \\
\hline Sex ratio $M: F \%$ & $70: 30$ & Almost all male \\
\hline Age at onset & $\begin{array}{l}\text { Second and third } \\
\text { decades }\end{array}$ & Fourth and fifth decades \\
\hline $\begin{array}{l}\text { Socioeconomic } \\
\text { status }\end{array}$ & $\begin{array}{l}\text { Usually poor, may } \\
\text { occur in others as well }\end{array}$ & $\begin{array}{l}\text { All strata of society equally } \\
\text { affected }\end{array}$ \\
\hline Course of diabetes & $\begin{array}{l}\text { More aggressive and } \\
\text { accelerated }\end{array}$ & Slower rate of progression \\
\hline Diabetes & Occurs in $>90 \%$ & About $50 \%$ of cases \\
\hline Pancreatic calculi & Occurs in $>90 \%$ & About $50 \%-60 \%$ of cases \\
\hline $\begin{array}{l}\text { Appearance of } \\
\text { pancreatic calculi }\end{array}$ & $\begin{array}{l}\text { Large and dense with } \\
\text { discrete margins }\end{array}$ & $\begin{array}{l}\text { Usually small and speckled } \\
\text { with ill defined margins }\end{array}$ \\
\hline Location of calculi & Always in large ducts & Usually in small ducts \\
\hline Ductal dilation & Usually marked & Usually mild \\
\hline Fibrosis of gland & Marked & Less severe \\
\hline Alcoholism & Absent by definition & Heavy alcohol abuse \\
\hline $\begin{array}{l}\text { Prevalence of } \\
\text { pancreatic cancer }\end{array}$ & Very high & $\begin{array}{l}\text { Higher than in the general } \\
\text { population }\end{array}$ \\
\hline
\end{tabular}

\section{Box 1: Definition}

- Tropical chronic pancreatitis is a juvenile form of chronic calcific, non-alcoholic pancreatitis, prevalent almost exclusively in the developing countries of the tropical world. Some of its distinctive features are younger onset, presence of large intraductal calculi, accelerated course of the disease, and high susceptibility to pancreatic cancer.

\section{Box 2: Clinical presentation}

The classical triad of clinical presentation in tropical chronic pancreatitis:

- Abdominal pain.

- Maldigestion leading to steatorrhoea.

- Diabetes (fibrocalculous pancreatic diabetes).

\section{Abdominal pain}

Abdominal pain is the predominant symptom and usually the presenting complaint in $30 \%-90 \%$ of patients in different series. ${ }^{42}{ }^{43}$ The pain is typically very severe, upper abdominal in location, radiates to the back, and is relieved by stooping forward or lying in a prone position. The severity of the pain tends to decrease and it becomes less frequent as the disease progresses and it usually disappears with onset of exocrine insufficiency and/or diabetes. ${ }^{44} 45$

\section{Pancreatic calculi}

In over $90 \%$ of patients with TCP, pancreatic calculi may be detected especially in the later stages. ${ }^{43}{ }^{46}$ The calculi are intraductal in location and are seen mostly on the right side of first and second lumbar vertebra on plain abdominal radiography. ${ }^{19}$ They may be solitary or multiple, and sometimes the entire pancreas may be studded with calculi (fig 2). The stones tend to be large, dense, and rounded with well defined edges in contrast to the small, speckled, ill defined stones in alcoholic chronic pancreatitis. ${ }^{47} 48$

\section{Maldigestion/steatorrhoea}

Patients with severe exocrine pancreatic insufficiency complain of passing bulky, frothy, or frankly oily stools. However, overt steatorrhoea is only present in about $20 \%$ of patients

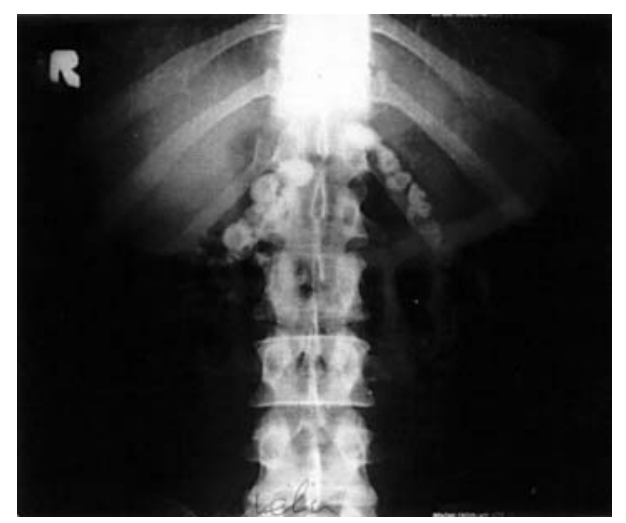

Figure 2 Plain radiograph of abdomen showing evidence of extensive pancreatic calculi in a patient with tropical chronic pancreatitis (reproduced from Mohan et $a^{44}$ with permission). 
with TCP. The low frequency of steatorrhoea is attributed to the low fat intake in the diet. When the fat intake of the diet was experimentally increased to $100 \mathrm{~g} /$ day from the average intake of $27 \mathrm{~g} /$ day, $76 \%$ of TCP patients developed steatorrhoea. ${ }^{49}$

\section{Diabetes}

Diabetes is an inevitable consequence of TCP commonly occurring a decade or two after the first episode of abdominal pain. ${ }^{44}$ Diabetes in TCP is called fibrocalculous pancreatic diabetes (FCPD), which is now classified under the broad category of other specific types both in the American Diabetes Association and the WHO consultation classifications of diabetes. ${ }^{45}$

In lean and undernourished individuals, the diabetes tends to be more severe and polyuria and polydipsia are the major presenting complaints. In the better nourished patients, the symptoms may be insidious and the diagnosis of FCPD is usually made during investigations for pain in the abdomen. Unless there is a high index of suspicion, the diagnosis is often delayed or missed.

One of the characteristic clinical features of FCPD is that despite requiring insulin for control, patients rarely become ketotic on withdrawal of insulin. This is attributed to the following factors:

1. Partial preservation of beta cell function as shown by Cpeptide studies..$^{50-53}$

2. Decreased glucagon reserve. ${ }^{54}$

3. Reduced supply of non-esterified fatty acid (NEFA), the fuel needed for ketogenesis, due to the loss of subcutaneous tissue.

4. Resistance to subcutaneous adipose tissue lipolysis to epinephrine.

5. Carnitine deficiency, affecting transfer of NEFA across mitochondrial membrane. ${ }^{445}$

While some studies have shown that patients with FCPD have insulin resistance to a similar degree to that seen in type 2 diabetic patients, ${ }^{56}$ others have not found insulin resistance to be a major factor in FCPD. ${ }^{57}$

Diabetes is usually very severe with a fasting blood glucose from $11.1-22.2 \mathrm{mmol} / \mathrm{l}(200-400 \mathrm{mg} / \mathrm{dl})$ and often requires the use of insulin for control. The mean daily insulin dose in a clinic based study was $40 \pm 12$ units/day especially when an insulin secretagogue was also used..$^{57}$ However there is a wide spectrum in the clinical presentation of FCPD with patients requiring only diet/oral drug treatment at one end of the spectrum to others who present with ketosis requiring insulin for survival at the other end (fig 3).

\section{PATHOLOGY}

TCP is a progressive disease, therefore the pathological findings depend on the stage of the disease at which the specimen is obtained. The pathological changes in TCP are mostly reported from postmortem or surgical specimens and several excellent reviews have been published..$^{59-61}$

\section{Gross findings}

The size of the pancreas varies inversely with the duration of the disease and can be as small as the little finger in advanced stages of the disease. The surface is nodular. The shape of the gland is distorted with loss of the normal lobular appearance.The gland is usually firm, fibrous, and gritty. However depending on the presence of fibrous tissue, cyst, or stone the consistency may vary in different regions of the pancreas.

The cut section of the pancreas shows the presence of homogenous areas with early to advanced fibrosis and

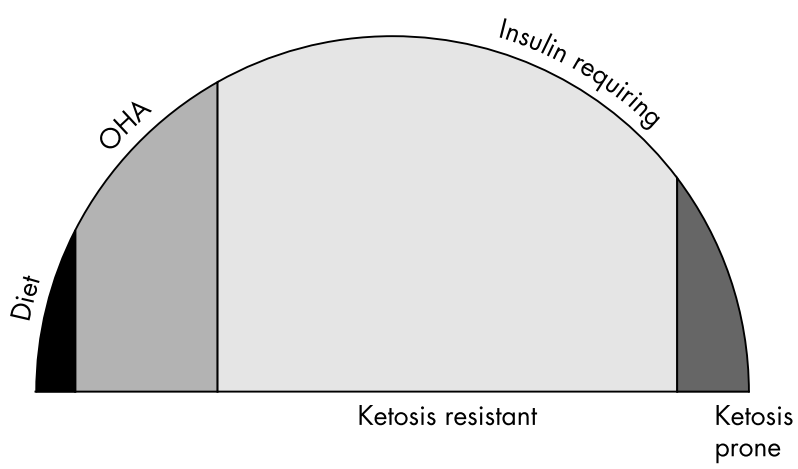

Figure 3 Spectrum of clinical severity of tropical chronic pancreatitis; OHA, oral hypoglycaemic agent (reproduced from Mohan et a ${ }^{44}$ with permission).

intraductal calculi of varying shapes and sizes with marked dilation of the duct and ductules. Areas of dilation and stenosis may be seen in the same gland. The gland may get displaced from its normal location due to uneven shrinkage and fibrous adhesion. Calculi may vary in size, shape, and colour. The size could range from small sand particles to large stones $4.5 \mathrm{~cm}$ long and weighing up to $20 \mathrm{~g}$ with the larger ones being located near the head and smaller ones near the tail. The shape of the calculi may be smooth, rounded, or staghorn-like and it is usually incarcerated in the main pancreatic duct or its major branches. Soft stones are formed by non-calcified protein plugs and caseous material. Sections of calcified stones show epithelial debris, fibrin, and mucinous material. Colour of the stones vary from chalky white to dirty white.

\section{Analysis of the stones}

Pancreatic calculi are composed of $95.5 \%$ calcium carbonate and small amount of calcium phosphate. In some stones, traces of magnesium, urate, and oxalate have also been identified. The calcium carbonate is predominantly the calcite, and rarely the vaterite form, as demonstrated by $x$ ray diffraction studies. ${ }^{62}$ Calculi have been found to have an amorphous nidus rich in iron, chromium, and nickel and a cryptocrystalline periphery containing a number of trace elements with a predominance of calcium. ${ }^{63}$

\section{Microscopy}

Microscopic examination reveals a thickened capsule and extensive intralobular and interlobular fibrosis not limited to any one zone or area. Interlobular fibrosis is characteristic of early cases and focal, segmental, or diffuse fibrosis of more advanced cases. Marked dilatation with periductular fibrosis is seen in the main duct, collecting ducts, and small ductules with denudation of the ductular epithelium and squamous metaplasia in some areas. The characteristic cellular infiltration of the pancreas is composed of lymphocytes and plasma cells, distributed mainly around the ducts. ${ }^{25} 59$ Some investigators report that there is virtually no inflammation in TCP and therefore prefer to call this condition as "tropical calcific pancreatopathy" rather than "tropical calcific pancreatitis". ${ }^{\prime 6} 61$

\section{Immunohistochemistry}

Immunohistochemistry has shown paucity of alpha cells and beta cells. ${ }^{6064}$ Immunohistochemistry studies show a decrease in the number of islets in some cases and hyperplasia in others. Nesidioblastosis may also be present in some patients (fig 4). There is an overall decrease in the percent of insulin and glucagon cells. The decrease in insulin 


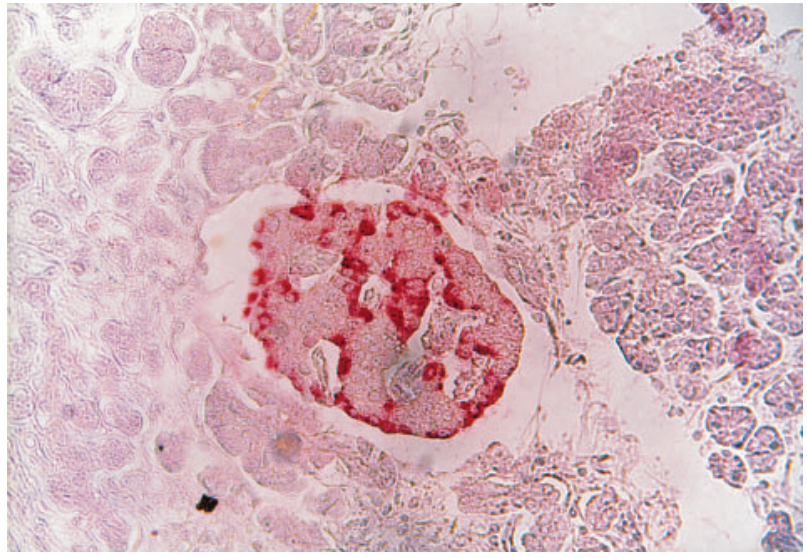

Figure 4 Histopathology showing "nesiodioblastosis" from a case of fibrocalculous pancreatic diabetes, showing islet tissue arising from ductal remnants (aminoethylcarbazole stain; magnification $\times 40$; reproduced from Govindarajan et al ${ }^{\beta 4}$ with permission).

positivity in the islets often correlates with the serum Cpeptide levels and inversely with the duration of diabetes. ${ }^{64}$

\section{AETIOPATHOGENESIS}

The exact aetiopathogenetic mechanisms still remain elusive. The following hypotheses have been proposed:

\section{Malnutrition.}

2. Role of cassava and other dietary toxins.

3. Familial and genetic factors.

4. Oxidant stress hypothesis and trace element deficiency states.

\section{Malnutrition}

The role of undernutrition in the aetiology of TCP has been reviewed in a number of papers. ${ }^{43}{ }^{62}$ This theory is based primarily on the initial observations that TCP affects the poor population of developing nations. It is indeed true that protein calorie malnutrition is present in many patients with TCP. However, recent observations question this hypothesis. ${ }^{828}{ }^{65-68}$ The large pockets of malnutrition in many parts of the world compared with the relative low frequency of TCP, for example Ethiopia, ${ }^{69}$ suggests that malnutrition by itself is unlikely to have an aetiological role. Further, kwashiorkor seldom leads to permanent pancreatic damage and pancreatic stones are absent even in advanced stages of kwashiorkor. Ironically, Kerala, a state in southern India with the highest literacy and lowest infant mortality rates, has the highest prevalence of TCP. Malnutrition thus could well be the effect rather than the cause of the disease since chronic pancreatitis with consequent malabsorption could itself lead to malnutrition. Also since protein calorie malnutrition is prevalent in

\section{Box 3: Proposed hypothesis for aetiopathogenesis of tropical chronic pancreatitis}

1. Malnutrition.

2. Cassava and other dietary toxins.

3. Familial and genetic factors.

4. Oxidant stress hypothesis and trace element deficiency states. many tropical countries, it is likely to be an accompanying factor in many diseases affecting the poor.

Recent studies on monkeys fed on high carbohydrate and low protein diet reported that they develop inflammatory and vascular changes in the pancreas and the heart and that the lesions mimicked those found in TCP. ${ }^{70}$ However, pancreatic calculi or diabetes were not observed in the study. Thus the relevance of these findings to TCP is unclear. The consensus therefore is that protein calorie malnutrition cannot be considered as the main aetiological factor of TCP.

\section{Cassava toxicity (cyanogen toxicity)}

Cassava (tapioca, Manihot esculenta) is a tuber consumed as a staple food by poor people in some parts of the world including Kerala. Cassava is known to contain cyanogenic glycosides such as linamarin and lotaustralin. Cyanide is normally detoxified in the body by conversion to thiocyanate, but this detoxification requires sulphur. In those with malnutrition, sulphur containing amino acids like methionine and cystine are deficient and the theory is that when these patients consume cassava, they develop pancreatitis leading to TCP.

McMillan and Geevarghese reported that rats develop transient hyperglycaemia on ingestion of cyanide which led them to conclude that there is role of cyanide in the aetiopathogenesis of tropical chronic pancreatitis. ${ }^{71}$ However potassium cyanide was used in these experiments and not cassava. Moreover, none of the rats developed permanent diabetes or chronic pancreatitits. Recent epidemiological and experimental studies further question the cassava hypothesis. TCP is prevalent in many parts of India and Africa where cassava is not consumed and TCP is also not seen in a rural West African population consuming a high cassava diet. ${ }^{72}$ Short term experimental feeding of cassava in animal models has produced conflicting results. ${ }^{73-75}$ A recent study on rats fed cassava diets for up to one year did not produce either pancreatitis or diabetes. ${ }^{76}$ Thus the cassava hypothesis lacks experimental support.

\section{Familial aggregation}

TCP sometimes affects many members of the same family $y^{517-79}$ and one study ${ }^{77}$ found 17 families with two or more affected members. In a more recent study, familial aggregation was seen in $8 \%$ of TCP patients. ${ }^{78}$ In some families, there was evidence of vertical transmission of TCP from the parents to the offspring, while in others, there was horizontal distribution of the disease among siblings. Familial aggregation suggests, but does not necessarily prove, a hereditary aetiology for TCP, since several family members could be exposed to the same toxic or other environmental factors.

\section{Genetic factors}

We looked for a genetic basis for this disease and in our first report suggested that FCPD might share common susceptibility genes with type 1 and type 2 diabetes. ${ }^{79}$ The islet regenerating gene (Reg gene) has been implicated in the pathogenesis of temperate zone pancreatitis. We therefore studied the association of FCPD with possible sequence variants of the Reg gene by RFLP analysis and found that mutation in the coding region of the Reg gene was unlikely to be the cause of FCPD. ${ }^{80} \mathrm{~A}$ recent report from Thailand also did not find any mutations of Reg 1 alpha and Reg I beta genes in FCPD patients. ${ }^{81}$

The molecular basis for hereditary pancreatitis has been attributed to mutations in exons 2 and 3 of the trypsinogen gene. ${ }^{82}{ }^{83} \mathrm{We}$ looked at these genes in our patients but found that FCPD was not linked to common mutations in the trypsinogen gene. ${ }^{84}$

SPINK 1 is a potent protease inhibitor and is considered to be a major protective mechanism in preventing inappropriate 
activation of pancreatic enzyme cascade by inhibiting up to $20 \%$ of trypsin activity. ${ }^{85}$ Since the inhibitory molecule provides the first line of defence against premature activation of trypsinogen inside the pancreas, it has recently attracted a lot of attention as a possible cause of chronic pancreatitis. Recently an association of hereditary pancreatitis has been shown with the SPINK 1 (serine protease inhibitor, Kazal type 1) gene. ${ }^{85}$ The association between the SPINK gene and TCP has now been reported by a number of groups. ${ }^{3}{ }^{46-90}$ Since all the above studies on TCP and others on other forms of chronic pancreatitis have shown a strong association with this gene, ${ }^{91}$ it is likely that this could be at least one of the genes predisposing to chronic pancreatitis in general and TCP in particular.

\section{Micronutrient deficiency and oxidant stress}

Chronic pancreatitis in white people has been linked to "heightened oxidative detoxification reactions" induced by cytochrome P450-1 within the pancreas and/or liver. ${ }^{92}{ }^{93}$ It is possible that several factors, including chronic induction of the cytochrome P450-1 subfamily of mono-oxygenase by xenobiotics (cigarettes, alcohol, occupational chemicals, dietary corn oil, and so forth) may be involved. Theophylline clearance (a measure of cytochrome P450-I activity in vivo) is faster in TCP subjects compared with controls ${ }^{94}$ suggesting a role of oxidant stress in causation of TCP. Studies on the antioxidant status of our TCP patients showed low levels of vitamin $C$ and $\beta$-carotene ${ }^{95}$ and this may well tilt the balance in favour of oxidant stress. Malnutrition induces a state of defective ability to scavenge free radicals, which could enhance the susceptibility for organ damage. Braganza et al suggested that free radical injury occurs in patients with alcoholic chronic pancreatitis as well as TCP. ${ }^{96}$ However, the free radical hypothesis is by no means proven and certainly merits further studies.

\section{INVESTIGATIONS}

Diagnosis of TCP is made by establishing evidence of chronic pancreatitis in patients who have the typical clinical features described earlier. If pancreatic calculi are present on plain abdominal radiography, the diagnosis is straightforward. However, calculi develop after several years of abdominal pain and about $10 \%$ of patients do not develop calculi. Hence the need for other diagnostic markers. Unfortunately, there are still no sensitive and specific non-invasive blood or urine tests to diagnose early stages of chronic pancreatitis. Even in the developed nations of the world, the diagnosis of chronic pancreatitis in adults or children is often elusive and made very late, only after ductal changes or calculi develop. As in other types of chronic pancreatitis, the diagnosis of TCP is seldom made in the early stages of the disease.

The investigation for a suspected case of TCP without pancreatic calculi is as follows:

- Tests of pancreatic structure
(A) Ultrasonography.
(B) Computed tomography.
(C) Endoscopic retrograde cholangiopancreatography.
(D) Endoscopic ultrasonography.

- Tests of pancreatic function

(A) Tests of exocrine pancreatic function.

(B) Tests of endocrine pancreatic function.

By ultrasonography of the abdomen it is possible to evaluate the size of the pancreas and also confirm intraductal location of calculi and the degree of fibrous. ${ }^{97}$ Figure 5 shows

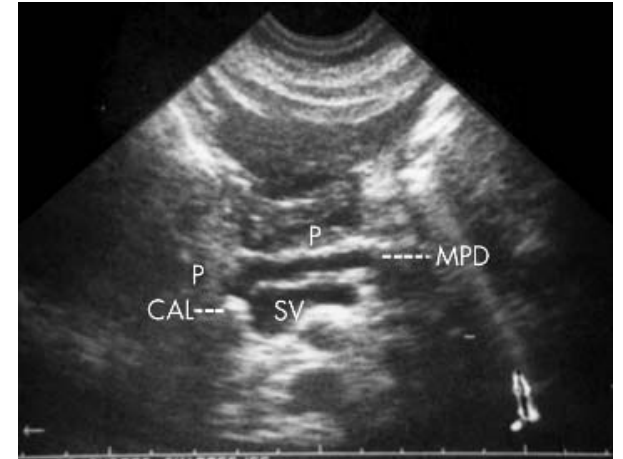

Figure 5 Typical ultrasound appearance with dilated pancreatic ducts with intraductal calculi (reproduced from Mohan et a ${ }^{44}$ with permission).

the typical ultrasound appearance with dilated pancreatic ducts with intraductal calculi. Imaging of smaller stones and diagnosis of pseudocyst is better on computed tomography. ${ }^{98}$

Endoscopic retrograde cholangiopancreatography (ERCP) studies help to confirm ductal dilatation particularly in the non-calcific causes of TCP. ERCP may show ductal tortuosity and dilation (fig 6), stenosis, obstruction, cyst formation, and the presence of calculi in the main pancreatic duct, side branches, and ductules. ${ }^{99}$

Endoscopic ultrasonography is an exciting new tool for diagnosis of chronic pancreatitis, especially at a relatively early stage. Comparisons with histology have shown the sensitivity and specificity of endoscopic ultrasonography to be $85 \%$ and $67 \%$ respectively. ${ }^{100}$ However more studies are required before accepting it as a standard diagnostic procedure for chronic pancreatitis.

\section{EXOCRINE PANCREATIC FUNCTION}

Exocrine pancreatic function in TCP has been studied by many workers using a variety of tests. Serum immunoreactive trypsin measurements have shown a spectrum of pancreatic involvement. In advanced stages of the disease, there is marked reduction of trypsin level while in early stages it may be subnormal or even elevated due to acute pancreatitis. ${ }^{101} 102$ When Lundh meal tests were performed, $93 \%$ of the TCP patients with calcification were reported to have low tryptic activity compared with $27 \%$ of the noncalcific variety. ${ }^{103}$ Secretin-pancreazymin tests revealed gross reduction in volume, bicarbonate, trypsin, and lipase content of the pancreatic secretion. ${ }^{77}$ The lactoferrin level of the pancreatic juice was found to be considerably higher in both normal controls and TCP subjects from India compared with their respective European counterparts.

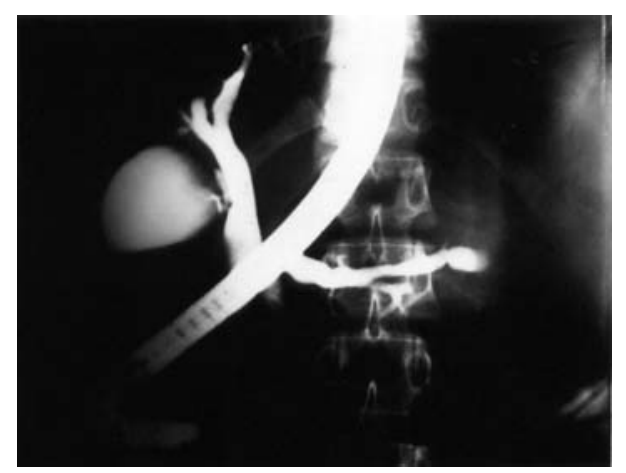

Figure 6 Endoscopic retrograde cholangiopancreatogram showing a markedly dilated pancreatic duct. 
There are several reports using faecal chymotrypsin as a screening test for evaluating exocrine pancreatic function in TCP patients. ${ }^{101} 104{ }^{105}$ We screened three groups of diabetic patients with FCPD and type 1 and type 2 diabetes and found that exocrine pancreatic insufficiency as shown by low faecal chymotrypsin levels (defined as $<5.8$ units/g of faecal mass) was present in $87.5 \%$ of patients with FCPD, $23.5 \%$ with type 1 diabetes, and $4.5 \%$ with type 2 diabetes. ${ }^{104}$ Low sensitivity is the only drawback with faecal chymotrypsin as it may not detect many mild cases of chronic pancreatitis, although its specificity is quite high. The usefulness of faecal chymotrypsin was compared with another tubeless test, namely the $N$-benzoyl L-tyrosyl-para-aminobenzoic acid (BT-PABA) test. $^{106}$ We found that although the faecal chymotrypsin test has a slightly lower sensitivity, it is simpler and considerably cheaper than the PABA test. We have also shown that the BT-PABA/p-aminosalicylic acid is an excellent test to diagnose TCP as it has a very high sensitivity and specificity. ${ }^{107}$

\section{ENDOCRINE FUNCTION}

Studies on C-peptide assay (a marker of pancreatic beta cell function) in FCPD patients indicate partial preservation of pancreatic beta cell function, in contrast to classical type 1 patients who have negligible beta cell reserve. Yajnik et al measured beta cell function in TCP patients with different degrees of glucose tolerance and found that plasma C-peptide concentrations were normal in those with normal or mildly impaired glucose tolerance. ${ }^{108}$ In the diabetic group, the Cpeptide levels were scattered; they were severely diminished in some while in the rest some beta cell reserve was present.

Plasma glucagon responses have been shown to be defective in patients with FCPD. ${ }^{54}$ In response to a glucose load, plasma glucagon levels rose sharply in subjects with primary forms of diabetes, whereas glucagon response was absent in the FCPD group.

\section{COMPLICATIONS}

\section{Complications due to chronic pancreatitis}

Complications due to chronic pancreatitis include pseudocysts, pancreatic abscesses, and ascites. Obstructive jaundice may also be occasionally seen, which can be due to common bile duct obstruction or associated carcinoma of the pancreas.

Pancreatic cancer is the most sinister complication of TCP. The risk of developing pancreatic cancer among patients with temperate zone chronic pancreatitis has been estimated to be 16.5-fold higher than age matched controls. ${ }^{109}$ In TCP patients the risk is probably higher. In one study, 185 TCP patients were followed up for an average of 4.5 years to assess the risk of pancreatic cancer. During this period, 34 patients died from all causes, and six deaths $(25 \%)$ were due to pancreatic cancer. When compared with the background pancreatic cancer rate (Madras Cancer Registry), the relative risk for pancreatic cancer in patients with TCP was 100 (95\% confidence interval 37 to 218). ${ }^{110}$ Augustine and Ramesh have also reported an increased risk of pancreatic carcinoma in TCP. ${ }^{111}$ While there are no direct comparisons with temperate zone pancreatitis, it appears that the risk of developing pancreatic cancer is higher in TCP than in alcoholic chronic pancreatitis. The only other type of pancreatitis that is highly prone to malignancy is hereditary pancreatitis where the risk ratio is 53 compared with the general population. ${ }^{112}$ The duration of exposure to inflammation seems to be the major factor involved in the transition to a malignant condition in chronic pancreatitis and smoking remains the strongest risk factor that is amenable to preventive intervention ${ }^{113}$ in temperate zone pancreatitis, while the risk factors for cancer in TCP remain unknown.

\section{Complications related to diabetes}

It was earlier believed that patients with FCPD do not develop long term complications of diabetes. This belief was based mainly on the assumption that being a secondary form of diabetes, patients with FCPD do not live long enough to develop specific diabetes related complications, which normally set in only after 10-15 years of diabetes. However, a series of studies from our group and others have shown that both microvascular and macrovascular complications do occur in patients with FCPD.

Rema et al reported advanced retinopathy in FCPD patients, ${ }^{114}$ which has been confirmed by others. ${ }^{115}$ Nephropathy was seen in $8.9 \%$ of our FCPD patients. Renal failure due to diabetic nephropathy has also been reported in other forms of pancreatic diabetes. ${ }^{116}$ Peripheral neuropathy ${ }^{117}$ and autonomic neuropathy ${ }^{118} 119$ have also been reported in those with FCPD.

Macrovascular complications are, however, rare in FCPD. This is believed to be due to three reasons: the patients are young, lean, and have low lipid levels. However, ischaemic heart disease, ${ }^{120}$ cerebrovascular accidents, ${ }^{121} 122$ and peripheral vascular disease have occasionally been reported..$^{123} 124$

Recently we did a comparative study on the prevalence of long term complications of diabetes in a large group of FCPD patients and a group of type 2 diabetic patients matched for age, sex, and duration of diabetes. The prevalence of all microvascular complications was found to be equal in both groups but macrovascular complications, particularly coronary heart disease, was significantly lower in the FCPD group. ${ }^{125}$

\section{NATURAL HISTORY}

Abdominal pain usually is the first symptom to manifest in the natural history of TCP. After prolonged periods varying from a few months to several decades, pancreatic calculi may be diagnosed by routine abdominal radiography. Until this point, both endocrine and exocrine pancreatic function of the subject may be found to be normal. After some months to years, glucose intolerance and/or exocrine pancreatic dysfunction may set in. Although this is the classical presentation, the first sign of the disease may be detection of pancreatic calculi, diabetes, or steatorrhoea. It is believed by most workers in the field that FCPD is the logical end point of TCP - that is, that TCP is the prediabetic stage of FCPD. However, recent reports from Bangladesh have suggested that TCP and FCPD are two different entities. ${ }^{126}{ }^{127}$ Based on long term follow up of large numbers of patients, we believe that FCPD is indeed the later diabetic stage of TCP for the following reasons:

1. TCP patients are younger than FCPD patients. ${ }^{128}$

2. TCP patients are also seen at the impaired glucose tolerance stage, ${ }^{128} 129$ which is considered to be a prediabetic stage.

\section{Box 4: Complications}

- Microvascular diabetic complications in FCPD: the prevalence of microvascular complications is similar to that seen in type 2 diabetes.

- Macrovascular complications are less common in FCPD because the patients are:

1. Young.

2. Lean.

3. Have lower lipid levels. 
3. The presence of SPINK 1 mutations in both TCP and FCPD, ${ }^{89}$ suggests a common genetic basis.

4. In a recent longitudinal follow up study we found that almost $50 \%$ of the TCP subjects without diabetes at baseline developed diabetes after a mean follow up of about seven years. The incidence of diabetes in the study group was 6.6 per 100 follow up years (Mohan et al, manuscript in preparation).

\section{LONG TERM SURVIVAL ANALYSIS}

In the 1960s and 70s, it was reported that TCP patients develop abdominal pain in childhood, diabetes by adolescence, and die of complications of diabetes such as chronic pancreatitis in early adulthood or in the prime of their life. ${ }^{8}$ Today TCP patients survive much longer, perhaps due to improved nutrition and better control of diabetes. We analysed the survival time of a cohort of 370 FCPD patients, taking the date of first occurrence of abdominal pain and the time of onset of diabetes as the two reference points. ${ }^{130}$ About $80 \%$ of patients were alive 35 years after the first episode of abdominal pain. The mean survival time after the diagnosis of diabetes was 25 years. The majority of deaths were associated with diabetes related causes, with diabetic nephropathy accounting for $40 \%$. Severe infections, pancreatic cancer, and pancreatitis related causes also contribute to the mortality of FCPD patients. However, the overall prognosis of these patients seems to have considerably improved during the last two to three decades.

\section{HETEROGENEITY OF TCP}

As described in earlier sessions, TCP is a highly variable (heterogenous) condition, in contrast to the earlier descriptions of the disease made three decades ago. ${ }^{819}$ Table 2 summarises the evidence for the heterogeneity which is seen with respect to the clinical, biochemical, ERCP, and histopathological features of TCP.

\section{MANAGEMENT \\ Abdominal pain \\ Analgesics}

Non-opioid analgesics should be the first choice and opioids should be avoided wherever possible for fear of addiction. Opioids may be considered for severe intractable episodes of pain which is very difficult to manage with non-opioids.

\section{Role of pancreatic enzyme supplements}

Pancreatic enzyme supplementation has been used traditionally to decrease the pain in all types of chronic pancreatitis because suppression of pancreatic secretion reduces intraductal pressure. Owyang et al reported that intraduodenal infusion of trypsin decreases pancreatic exocrine secretion

Table 2 Heterogeneity (variability) in fibrocalculous pancreatic diabetes 6

\begin{tabular}{|c|c|}
\hline $\begin{array}{l}\text { 1. Symptoms } \\
\text { 2. Carbohydrate } \\
\text { intolerance } \\
\text { 3. B cell reserve } \\
\text { 4. Response to therapy } \\
\text { 5, Proneness to ketosis } \\
\text { 6. Exocrine dysfunction } \\
\text { 7. ERCP } \\
\text { 8. Histopathology }\end{array}$ & $\begin{array}{l}\text { Asymptomatic, marked symptoms } \\
\text { Normal glucose tolerance test, impaired glucose } \\
\text { tolerance, overt diabetes } \\
\text { Good, poor, and negligible } \\
\text { Diet alone/oral agents/insulin } \\
\text { Ketosis resistant/ketosis prone } \\
\text { Only after provocative tests clinical steatorrhoea } \\
\text { Absent to mild ductal changes } \\
\text { Marked ductal changes (more common) } \\
\text { Mild changes: calculi absent or small (less } \\
\text { common) } \\
\text { Marked changes: extensive fibrosis/ductal } \\
\text { dilatation/multiple calculi (more common) }\end{array}$ \\
\hline
\end{tabular}

through suppression of cholycystokinin, ${ }^{131}$ but other studies do not support these findings. ${ }^{132}{ }^{133}$ The evidence for use of pancreatic enzyme in pain relief is, however, controversial with some trials showing benefit ${ }^{134-136}$ and others no benefit..$^{137} 138$ One of the possible reasons for the lack of benefit may be that the enteric coated enzyme preparations do not get released in the duodenum and hence are not capable of activating the negative feedback mechanism. The present consensus is that pancreatic enzyme supplement may be used as an initial treatment modality for relief of pain. ${ }^{139}$ Preparations used should contain large amount of protease ( $>25000$ USP units per tablet) and be given in a dosage of four to eight capsules or tablets four times daily. ${ }^{140}$

\section{Antioxidants}

Uden et al reported that antioxidants supplementation significantly decreased analgesic requirement in patients with alcoholic chronic pancreatitis. ${ }^{141}$ However the study population was heterogeneous and antioxidants and placebo tablets were not identical in their study. Antioxidants supplementation have also been shown to decrease pain in another recent study of TCP patients. ${ }^{142}$ Further studies are required for confirming the efficacy of antioxidants.

\section{Steatorrhoea}

Malabsorption resulting in steatorrhoea can be managed effectively by low fat diet. We have earlier reported that pancreatic enzymes supplementation help to reduce steatorrhoea and also improve the quality of life. ${ }^{143}$

\section{Diabetes}

The principles of management of diabetes remains the same in FCPD as in other types of diabetes except that a more liberal calorie and protein intake may be advised because of the features of undernutrition and leanness. Oral hypoglycaemic agents may be useful in cases with mild diabetes and relatively early in the course of the disease. The majority of patients, however, need insulin for control of diabetes and to improve their general health and sense of wellbeing.

\section{SURGERY}

Often, the abdominal pain can be intractable and difficult to manage. When there is no response to medical treatment, surgical intervention is indicated. Various surgical interventions have been tried with fairly good results. ${ }^{144145}$ Many of these procedures are beneficial with respect to alleviation alteration of pain, although some patients may experience a relapse. There are some reports which suggest that after surgery the mean daily insulin requirement may decrease. ${ }^{20145} 146$ These changes are usually transient and the

\section{Box 5: Medical management}

- Abdominal pain:

- Analgesics.

- Pancreatic enzyme supplement.

- Antioxidants.

- Steatorrhoea:

- Pancreatic enzyme supplements.

- Diabetes:

- Oral hypoglycaemic agents for early cases.

- Insulin is needed for majority of patients. 


\section{Key references}

- Mohan V, Nagalotimath SJ, Yajnik CS, et al. Fibrocalculous pancreatic diabetes. Diabetes Metab Rev 1998;14:153-70.

- Mohan V, Pitchumoni CS. Tropical chronic pancreatitis. In: Beger HG, Warshaw AL, Buchler MW, et al, eds. The pancreas. Vol 1. London: Blackwell Science, 1998:688-97.

- Pitchumoni CS. Special problems of tropical pancreatitis. J Clin Gastroenterol 1985;13:941-59.

- Geevarghese PJ. Pancreatic diabetes. Bombay: Popular Prakashan, 1968:110-15.

- Mohan V, Mohan R, Susheela L, et al. Tropical pancreatic diabetes in South India: heterogeneity in clinical and biochemical profile. Diabetologia 1985;28:229-32.

- Yajnik CS, Shelgikar KM, Sahasrabudhu RA, et al. The spectrum of pancreatic exocrine and endocrine (beta cell) function in tropical calcific pancreatitis. Diabetologia 1990;33:417-21.

diabetic status appears to be largely unaffected by surgery. There is, however, improvement of general health and quality of life, particularly in those with severe intractable pain.

The usual surgical procedures used are ductal decompression and drainage techniques like side to side pancreaticojejunostomy (Peustow's procedure) or distal pancreaticojejunostomy (Duval's procedure). ${ }^{147}$ Ablative procedures like partial or subtotal pancreatectomy are used in those with intractable pain. ${ }^{147}$

Recurrent pain after drainage procedures has often been reported. Stenosis of the anastomosis, retained calculi causing cysts or abscesses, and internal postoperative herniations, sometimes a twisting of the Roux loop used for the pancreatojejunal anastomosis, are some of the causes identified for recurring pain. Pancreatic tumour, however, is the most important condition to be excluded in any patient with persistent or recurrent pain after a drainage procedure.

Extracorporeal shock wave lithotripsy and stone dissolution and endoscopic stone removal are often successful, but the mere removal of stones may not guarantee relief of pain.

\section{FUTURE PERSPECTIVES}

TCP is a unique tropical form of chronic pancreatitis seen exclusively in some tropical countries of the world. The prognosis of TCP patients has improved in the last two to three decades and the understanding of the natural history of TCP is also beginning to evolve but its aetiopathogenesis continues to be elusive. Future studies should explore the pathogenetic mechanisms that could pave the way for prevention of this condition. Early diagnosis and newer therapeutic approaches could help to ensure better survival and prognosis of patients with TCP.

\section{MULTIPLE CHOICE QUESTIONS (ANSWERS AT END OF REFERENCES)}

1. The most prevalent form of chronic pancreatitis in the tropics is:
(A) Alcoholic
(B) Hereditary
(C) Idiopathic
(D) TCP

2. The major component in the composition of pancreatic stone is:
(A) Calcium carbonate
(B) Calcium phosphate
(C) Magnesium
(D) Oxalate

3. The characteristic microscopic feature of TCP is:
(A) Diffuse and progressive fibrosis of the pancreas
(B) Absence of fibrosis
(C) Increase in number of islet cells

4. The gene most commonly implicated with pathogenesis of TCP is:
(A) Reg
(B) CFTR
(C) SPINK 1
(D) PRSS 1

5. The occurrence of microvascular complications of diabetes in FCPD patients is:
(A) Very rare
(B) Rare
(C) As common as in type 2 diabetes
(D) Not seen at all

6. The unique feature distinguishing TCP from alcoholic chronic pancreatitis is:
(A) TCP occurs at a younger age
(B) In TCP calculi are larger and invariably found in large ducts
(C) TCP patients are more prone for pancreatic malig- nancy
(D) All of the above

\section{Authors' affiliations}

K K Barman, G Premalatha, V Mohan, M V Diabetes Specialities Centre, Madras Diabetes Research Foundation, Chennai, India

\section{REFERENCES}

1 WHO Study Group. Report on diabetes mellitus. WHO technical report series, No 727. Geneva: WHO, 1985.

2 Mohan V, Premalatha G. Fibrocalculous pancreatic diabetes. International Journal of Diabetes 1995; 3:71-82.

3 Consensus statement. International workshop on types of diabetes peculiar to the tropics, 17-19, October 1995, Cuttack, India. Acta Diabetologica Latina 1996;33:62-4.

4 Anonymous. Report of the expert committee on the diagnosis of diabetes mellitus. Diabetes Care 1997;20:1183-97.

5 Alberti KGMM, Zimmet PZ. Definition, diagnosis and classification of diabetes mellitus and its complications. Part 1: diagnosis and classification of diabetes mellitus: provisional report of a WHO consultation. Diabet Med 1998;78:539-53.

6 Chari ST, Mohan V, Jayanthi V, et al. Comparative study of the clinical profile of alcoholic pancreatitis and tropical chronic pancreatitis in South India. Pancreas 1991;7:2-58.

7 Zuidema PJ. Cirrhosis and disseminated calcification of the pancreas in patients with malnutrition. Trop Geogr Med 1959;11:70-74.

8 Geevarghese PJ. Pancreatic diabetes. Bombay: Popular Prakashan, 1968:110-115.

9 Pitchumoni CS. Special problems of tropical pancreatitis. J Clin Gastroenterol 1985;13:941-59.

10 Kini MG. Multiple pancreatic calculi with chronic pancreatitis. Br J Surg 1937;25:705.

11 Elizabeth T, Stephen PM. Pancreatic calculi. J Indian Med Assoc 1954;24:126. 
12 Kinnear TWA. Patterns of diabetes in a Nigerian teaching hospital. W Afr Med J 1963;40:228-33.

13 Shaper G. Chronic pancreatic disease and protein malnutrition. Lancet 1960;ii:1223-4.

14 Mngola EN. Diabetes mellitus in the African enviornment-the dilemma. In: Mngola EN, ed. Diabetes 1982. Proceedings of the II Congress of the IDF. Amsterdam: Excerpta Medica, 1983:309-13.

15 Dani R, Penna FJ, Nogueria CED. Etiology of chronic pancreatitis in Brazil: a report of 329 consecutive cases. Int J Med 1976:316-20.

16 Vannasaeng S, Nitiyanant W, Vachayanrat A, et al. Characteristics of diabetes with onset under 30 years in Thailand. In: Mimura G, ed. Childhood and juvenile diabetes mellitus. Amsterdam: Excerpta Medica, 1998:75-9.

17 Azad Khan AK, Banik NG, Mahatab H. Malnutrition related diabetes mellitus in Bangladesh. In: Rifkin H, Colwell JA, Taylor SI, eds. ICS 1000. Amsterdam: Excerpta Medica, 1991:944-9.

18 Illangovekara V. Malnutritiion related diabetes in Sri Lanka fact or fiction? Journal of the Ceylon College of Physicians 1995;28:16-25.

19 Geevarghese PJ. Calcific pancreatitis. Bombay: Varghese Publishing House, 1985.

20 Augustine P. Discussion on epidemiology and clinical features of tropical calcific pancreatitis. In: Kumar N, Acharya SK, eds. Tropical calcific pancreatitis. Trivandrum: Roussel Scientific Institute, 1997:41-4.

21 Balakrishnan V. Tropical pancreatitis (pancreatic tropicale). In: Bernades $P$, Hugier M, eds. Maladies du pancreas exocrine. Paris: Doin, 1987:207-27.

22 Mathew Roy VC. Malnutrition related diabetes mellitus - a review. Diabetes bulletin. Hyderabad: Research Society for study of Diabetes in India, 1996:7-12.

23 Pai KN, Ramachandran A. Diabetes mellitus in the endemic pancreatic syndrome of Kerala. In: Kumar V, ed. Disorders of carbohydrate metabolism. New Delhi: Arnold Heinmann, 1974:139-50.

24 Tripathy BB, Samal KC. Chronic calcific pancreatitis in the young in Orissa. In: Balakrishnan V, ed. Chronic pancreatitis in India. Trivandrum: Indian Society of Pancreatology, 1987:87-96.

25 Nagalotimath SJ. Pancreatic in Karnataka. A note on pathology. In: Balakrishnan V, ed. Chronic pancreatitis in India. Trivandrum: Indian Society of Pancreatology, 1986:105-111.

26 Viswanathan M. Pancreatic diabetes in India: an overview. In: Podolsky S, Viswanathan M, eds. Secondary diabetes; the spectrum of diabetic syndromes. New York: Raven Press, 1980:105-16.

27 Moses SGP, Kannan V. The clinical profile of undernourished diabetics aged 30 or less with associated complication in Madras. In: Baba S, Goto Y, Fukui I, eds. Diabetes mellitus in Asia. Amsterdam: Excerpta Medica, 1976:259-62.

28 Mohan V, Mohan R, Susheela L, et al. Tropical pancreatic diabetes in South India: heterogeneity in clinical and biochemical profile. Diabetologia 1985;28:229-32.

29 Pendsey SP, Doongaii SK, Vaidya MG. Clinical profile of fibrocalculous pancreatic diabetes (FPCD) from Vidarbha region. Journal of the Diabetic Association of India 1990;30:7.

30 Bhattacharya PK, Mohan V. Fibrocalculous pancreatic diabetes in Tripura The Antiseptic 1990;87:161-5.

31 Mittal N, Mehrotra R, Agarwal G, et al. The clinical spectrum of fibrocalculous pancreatic diabetes in north India. Natl Med J India 2002;15:327-31.

32 Anand BS. Clinical profile of chronic pancreatitis in Delhi. In: Balakrishnan V, ed. Chronic pancreatitis in India. Trivandrum: Indian Society of Pancreatology, 1987:15-22.

33 Balaii LN, Tandon RK, Tandon BN, et al. Prevalence and clinical features of chronic pancreatitis in Southern India. Int J Pancreatol 1993;15:29-34.

34 Lin $Y$, Tamakashi A, Matsuna S, et al. Nation wide epidemiological survey of chronic pancreatitis in Japan. J Gastroenterol 2000;35:135-41.

35 Riela A, Zinsmeister AR, Melton $\sqcup$, et al. Increasing incidence of pancreatic cancer among women in Olmsted County, Minnesota, 1940 through 1988. Mayo Clin Proc 1992:67:839-45.

36 Copenhagen Pancreatic Study Group. An interim report from a prospective epidemiological multicentre study. Scand J Gastroenterol 1981;16:305-12.

37 Robles-Diaz G, Vargas F, Uscanga L, et al. Chronic pancreatitis in Mexico city. Pancreas 1990;5:479-83.

38 Mohan V, Chari S, Ramachandran A, et al. Fibrocalcific pancreatic diabetes and obesity. Diabetes Res Clin Pract 1990;8:161-6.

39 Premalatha G, Mohan V. Fibrocalculous pancreatic diabetes in infancytwo case reports. Diabetes Res Clin Pract 1990;25:137-40.

40 Mohan V, Ramachandran A, Vishwanathan M. Childhood onset fibrocalculous pancreatic disease. International Journal of Diabetes in Developing Countries 1990;10:24-6.

41 Mohan V, Suresh S, Suresh I, et al. Fibrocalculous pancreatic diabetes in the elderly. J Assoc Physicians India 1989;37:342-5.

42 Viswanathan M. Pancreatic diabetes in India: an overview, In: Podolsky S, Viswanathan $M$, eds. Secondary diabetes: the spectrum of the diabetes syndromes. New York: Raven Press, 1980:105.

43 Balakrishnan V. Chronic calcifying pancreatitis in the tropics. Indian J Gastroenterol 1984;3:65-7.

44 Mohan V, Nagalotimath SJ, Yajnik CS, et al. Fibrocalculous pancreatic diabetes. Diabetes Metab Rev 1998;14:153-70.

45 Mohan V, Pitchumoni CS. Tropical chronic pancreatitis. In: Beger HG, Warshaw AL, Buchler MW, eds. The pancreas. Vol 1. London: Blackwell Science, 1998:688-97

46 Narendranathan $\mathrm{M}$. Chronic calcific pancreatitis in the tropics. Trop Gastroenterol 1981;2:40-5
47 Mohan V, Alberti KGMM. Diabetes in the tropics. In: Alberti KGMM Defronzo RA, Keen $\mathrm{H}$, eds. International textbook of diabetes mellitus. $1 \mathrm{st} \mathrm{Ed}$. Chichester: John Wiley, 1999:177-96.

48 Chari ST, Jayanthi V, Mohan V, et al. Radiological appearance of pancreatic calculi in tropical and alcoholic chronic pancreatitis. J Gastroenterol Hepatol 1992; 7:42-4

49 Balakrishnan V, Sauniere JH, Hariharan $M$, et al. Diet, pancreatic function and chronic pancreatitis in South India and France. Pancreas 1988;3:30-5.

50 Mohan V, Snehalatha C, Ramachandran A, et al. Pancreatic beta cell function in tropical pancreatic diabetes. Metabolism 1983;32:1091-2.

51 Sood R, Ahuja MMS, Karmarkar MG. Serum C-peptide levels in young ketosis resistant diabetics. Indian J Med Res 1983;78:661-4.

52 Vannasaeng S, Nitiyanant TW, Vachayanrat A, et al. C-peptide secretion in calcific tropical pancreatic diabetes. Metabolism 1986;35:814-17.

53 Samal KC, Das S, Parija CR, et al. C-peptide responses to glycaemic stimuli. $J$ Assoc Physicians India 1987;37:362-4.

54 Mohan V, Snehalatha C, Ramachandran A, et al. Plasma glucagon responses in tropical fibrocalculous pancreatic diabetes. Diabetes Res Clin Pract 1990;9:97-101.

55 Yajnik CS, Shelgikar KM, Naik SS, et al. The ketosis resistance in fibrocalculous pancreatic diabetes: clinical observations and endocrine metabolic measurements during oral glucose tolerance test. Diabetes Res Clin Pract 1992;15:149-56.

56 Mohan V, Ramachandran A, Vijaya Kumar G, et al. Insulin resistance in fibrocalculous (tropical) pancreatic diabetes. Horm Metab Res 1988;12:746-8

57 Mehrotra RN, Bhatia E, Choudhury G. Beta cell function and insulin sensitivity in tropical calcific pancreatitis from North India. Metabolism 1997; 46:441-4

58 Mohan V, Ahmed MR, Ramachandran A, et al. Clinical profile of tropical pancreatic diabetes at Madras. In: Balakrishnan V, ed. Chronic pancreatitis in India. Trivandrum: Indian Society of Pancreatology, 1987:97-104.

59 Nagalotimath SJ. Pancreatic pathology in pancreatic calcification with diabetes. In: Podolsky S, Viswanathan M, eds. Secondary diabetes: the spectrum of diabetic syndromes. New York: Raven Press, 1980:117-45.

60 Nair B. Pathology of tropical calcific pancreatitis. In: Kumar N, Acharya SK, eds. Tropical calcific pancreatitis. Kerala: Roussel Scientific Institute, 1994:83-90

61 Nair B, Latha P. Pancreas in chronic pancreatitis in India. In: Balakrishnan V, ed. Trivandrum: Indian Society of Pancreatology, 1987:115-20.

62 Schultz AC, Moore PB, Geevarghese PJ, et al. X-ray diffraction studies of pancreatic calculi associated with nutritional pancreatitis. Dig Dis Sci 1986;31:476-80

63 Pitchumoni CS, Viswanathan KV, Geevarghese PJ, et al. Ultrastructure and elemental composition of human pancreatic calculi. Pancreas 1987;2:152-8.

64 Govindarajan M, Mohan V, Deepa R, et al. Histopathology and immunohistochemistry of pancreatic islets in fibrocalculous pancreatic diabetes. Diabetes Res Clin Pract 2001;51:29-38.

65 Rao RH, Yainik CS. Malnutrition related diabetes: time to think? Diabetes Care 1996;19:1014-17.

66 Abu-Bakare A, Taylor R, Gill GV, et al. Tropical or malnutrition related diabetes. Lancet 1986;i: 1 135-8.

67 Rao RH. The role of undernutrition in the pathogeness of diabetes mellitus. Diabetes Care 1984:7:595-600.

68 GeeVarghese PJ, Pitchumoni CS, Nair SR. Is protein malnutrition a initiating cause of pancreatic calcification? J Assoc Physicians India 1969;14:417-19.

69 Lester FT. A search for malnutrition related diabetes mellitus in an Ethiopian diabetes clinic. Bulletin of the International Diabetes Federation 1984:29:14.

70 Sandhyamani S. Vasculopathic and cardiomyopathic changes induced by low-protein high carbohydrate tapioca based diet in bonnet monkey. Vasculopathic and cardiomyopathic changes in induced malnutrition. Am J Cardiovasc Pathol 1992:4:41-50.

71 McMillan DE, Geevarghese PJ. Dietary cyanide and tropical malnutrition diabetes. Diabetes Care 1979;2:202-8.

72 Tuescher T, Rosman JB, Baillod R, et al. Absence of diabetes in rural west African population with a high carbohydrate/cassava diet. Lancet 1987;i:765-8.

73 Pushpa M. Chronic cassava toxicity: an experimental study. Thiruvananthapuram: University of Kerala, 1980

74 Akpan JO. The role of dietary cyanogens in diabetes mellitus. Clin Res 1984;32:389(A).

75 Kamalu BP. The effect of a nutritionally balanced cassava (Manihot esculenta Crantz) diet on endocrine function using the dog as a model 1. Br J Nutr 1991;61:365-72.

76 Mathangi DC, Deepa R, Mohan V, et al. Long term ingestion of cassava (tapioca) does not produce diabetes or pancreatitis in the rat model. Int J Pancreatol 2000;27:203-8.

77 Pitchumoni CS. Familial pancreatitis. In: Pai KN, Soman CR, Varghese R, eds. Pancreatic diabetes. Trivandrum: Geo Printers, 1970:46-8.

78 Mohan V, Chari S, Hitman GA, et al. Familial aggregation in tropical firbrocalculous pancreatic diabetes. Pancreas 1989:4:690-3.

79 Kambo PK, Hitman GA, Mohan V, et al. The genetic predisposition to fibrocalculous pancreatic diabetes. Diabetologia 1989;32:45-51.

80 Hawrami K, Mohan V, Bone A, et al. Analysis of islet regenerating (reg) gene polymorphisms in fibrocalculous pancreatic diabetes. Pancreas 1997; 14:122-5.

81 Boonyasrisawat W, Pulsawat P, Yenchtsomanus PT, et al. Analysis of the reg 1 alpha and reg 1 beta gene transcripts in patients with fibrocalculous pancreatopathy. South East Asian J Trop Med Public Health 2002:33:365-72. 
82 Whitcomb DC. Genetic predisposition to acute and chronic pancreatitis. Med Clin North Am 2000;84:531-47.

83 Whitcomb DC. Hereditary pancreatitis: new insights into acute and chronic pancreatitis. Gut 1999:45:317-22.

84 Hassan Z, Mohan V, McDermott MF, et al. Pancreatitis in fibrocalculous pancreatic diabetes mellitus is not associated with common mutations in the trypsinogen gene. Diabetes Metab Res Rev 2000;16:454-7.

85 Whitcomb DC, Gorry MC, Preston RA, et al. Hereditary pancreatitis is caused by a mutation in the cationic trypsinogen gene. Nat Genet 1996;14:141-5

86 Hassan Z, Mohan V, Ali L, et al. SPINK1 is a major gene for susceptibility to fibrocalculous pancreatic diabetes in subjects from southern Indian subcontinent. Am J Hum Genet 2002;71:964-8.

87 Chandak GR, Idris MM, Reddy DN, et al. Mutations in the pancreatic secretory trypsin inhibitor gene (PSTI/SPINK1) rather than the cationic trypsinogen gene (PRSS1) are significantly associated with tropical calcific pancreatitis. J Med Genet 2002;39:347-51.

88 Suman A, Schneider A, Rossi L, et al. SPINK1 mutations in tropical pancreatitis and diabetes patients from Bangladesh. Pancreas $2001 ; 23: 462-7$.

89 Bhatia E, Choudhuri G, Sikora SS, et al. Tropical calcific pancreatitis: strong association with SPINK 1 trypsin inhibitor mutation. Gastroenterology 2002;123:1020-5

90 Schneider A, Suman A, Rossi L, et al. SPINK 1/PSTI 1 mutation are associated with tropical pancreatitis and type 2 diabetes in Bangladesh. Gastroenterology 2002; 123:1026-30.

91 Pfutzer RH, Barmada MM, Brunskill AP, et al. SPINK/PSTI polymorphisms act as disease modifiers in familial and idiopathic chronic pancreatitis. Gastroenterology 2000;1 19:615-23.

92 Braganza JM. The pancreas. In: Pounder RG, ed. Recent advances in gastroenterology. London: Churchill Livingstone, 1988:251-80

93 Braganza JM. Free radicals and pancreatitis. In: Rice-Evans C, Dormandy TL, eds. Free radicals: chemistry, pathology and medicine. London: Richelieu Press, 1988:357-81

94 Chaloner C, Sandle LN, Mohan V, et al. Evidence for induction of cytochrome $\mathrm{p}-4501$ in patients with tropical chronic pancreatitis. International Journal of Clinical Pharmacology, Therapy, and Toxicology 1990;28:235-40.

95 Braganza JM, Schofield D, Snehalatha $C$, et al. Micronutrient antioxidant status in tropical compared with temperate zone chronic pancreatitis. Scand J Gastroenterol 1993;28:1098-104.

96 Braganza JM, Sherry J, Indira P, et al. Xenobiotics and tropical chronic pancreatitis. Int J Pancreatol 1990:222-45.

97 Mohan V, Sreeram D, Ramachandran A, et al. Doraiswamy KRI. Ultra sonography of the pancreas in tropical pancreatic diabetes. Acta Diabetologica Latina 1985;22:143-5.

98 Joseph S. Imaging of pancreas in tropical pancreatitis: role of computerized tomographic scanning. In: Kumar N, Acharya SK, eds. Tropical calcific pancreatitis. Kerala: Roussel Scientific Institute, 1994:69-76.

99 Balakrishnan V, Hariharan M, Rao VRK, et al. Endoscopic pancreatography in chronic pancreatitis of the tropics. Digestion 1985;32:128-31.

100 Zimmerman MJ, Mishra G, Lewin D, et al. Comparison of EUS findings with histopathology in chronic pancreatitis. Gastrointest Endosc 1995;41:AB301 (abstract).

101 Yajnik CS, Sahasrabudhe RA, Naik SS, et al. Exocrine pancreatic function (serum immunoreactive trypsin, fecal chymotrypsin and pancreatic isomylase) in Indian diabetics. Pancreas 1990;5:631-8.

102 Yajnik CS, Katrak A, Kanitkar SV, et al. Serum immunoreactive trypsin in tropical pancreatic diabetes syndrom. Ann Clin Biochem 1989;26:69-73.

103 Punnose J, Balakrishnan V, Bhadran A. Exocrine pancreatic function in chronic pancreatitis with and without calcification. Indian J Gastroenterol 1987;6:85-6.

104 Mohan V, Snehalatha C, Ahmed MR, et al. Exocrine pancreatic function in tropical fibrocalculous pancreatic diabetes. Diabetes Care 1989;12:145-7.

105 Wiyono P. Exocrine and endocrine pancreatic function in malnutrition related diabetes mellitus (MRDM) in Yogjakarta. Kobe J Med Sci 1988;34:215-26.

106 Mohan V. Comparison of exocrine pancreatic function by two tubeless tests in fibrocalculous pancreatic diabetes (FCPD) and insulin dependent diabetes mellitus (IDDM). International Journal of Diabetes in Developing Countries 1996;16:61-4.

107 Gagee P, Pembertonn P, Lobley R, et al. The BT-PABA/PAS test in tropical diabetes. Clin Chim Acta 1992;212:103-11.

108 Yainik CS, Shelgikar KM, Sahasrabudhu RA, et al. The spectrum of pancreatic exocrine and endocrine (beta cell) function in tropical calcific pancreatitis. Diabetologia 1990;33:417-21.

109 Lowenfels AB, Maisonneuve P, Cavallini A, et al. Pancreatitis and the risk of pancreatic cancer International study group. N Engl J Med 1993:328: 1433-7.

110 Chari ST, Mohan V, Pitchumoni CS, et al. Risk of pancreatic carcinoma in tropical calcific pancreatitis. Pancreas 1993;9:62-6

111 Augustine $\mathbf{P}$, Ramesh $\mathrm{H}$. Is tropical pancreatitis pre-malignant? Am J Gastroenterol 1992:87:1005-8.

112 Lowenfels AB, Maisonneuve P, DiMagno EP, et al. Heriditary pancreatitis and the risk of pancreatic cancer. Intrenational Heriditary Pancreatitis Study Group. J Natl Cancer Inst 1997;89:442-6.

113 Maisonneuve $\mathbf{P}$, Lowenfels $A B$. Chronic pancreatitis and pancreatic cancer. Dig Dis 2002;20:32-7.

114 Rema M, Rajendran B, Ramachandran A, et al. Retinopathy in tropical pancreatic diabetes. Arch Ophthalmol 1985;103:1487-9.
115 Shelgikar KM, Yajnik CS, Mohan V. Complications in fibrocalculous pancreatic diabetes - the Pune and Madras experience. International Journal of Diabetes in Developing Countries 1995;15:70-5.

116 Levitt NS, Adams G, Salmon J, et al. The prevalence and severity of microvascular complications in pancreatic diabetes and IDDM. Diabetes Care 1995; 18:971-4

117 Ramachandran A, Mohan V, Kumaravel TS, et al. Peripheral neuropathy in tropical pancreatic diabetes. Acta Diabetologica Latina 1985;23:135-40.

118 Govindan R, Das AK. Cardiac autonomic function in fibrocalculous pancreatic diabetes. Acta Diabetol 1993:30:30-6.

119 Mohan V, Sastry NG. Premalatha G. Autonomic dysfunction in non insulin dependent diabetes mellitus and fibrocalculous pancreatic diabetes in South India. Diabet Med 1996; 13:1038-43.

120 Mohan V, Premalatha G, Sastry NG. Ischaemic heart disease in south India. International Journal of Diabetes in Developing Countries 1995;15:64-9.

121 Mohan V, Ramachandran A, Viswanathan M. Two case reports of macrovascular complications in fibrocalculous pancreatic diabetes. Acta Diabetol 1989:26:345-9.

122 Sastry NG, Mohan V. Hemiplegia in a patient with fibrocalculous pancreatic diabetes. J Assoc Physicians India 2000;48:1129.

123 Mohan V, Premalatha G, Sastry NG. Peripheral vascular disease in non insulin dependent diabetic mellitus in south India. Diabetes Res Clin Pract 1995:27:235-40.

124 Chattopadhyay PS, Mukhopadhyay J, Chattopadhyay R, et al. Macrovascular disease is not that uncommon in fibrocalculous pancreatic diabetes (FCPD). Diabetes Care 1994;17:462-3.

125 Barman KK, Padmanabhan M, Premalatha G, et al. Prevalence of diabetic complications with fibrocalculous pancreatic diabetic patietns and type 2 diabetic patients - cross sectional comparative study. Journal of Diabetes and its Complications 2003 (in press).

126 Rossi L, Pfutzer RH, Parvin S, et al. SPINK1/PSTI mutations are associated with tropical pancreatitis in Bangladesh. Pancreatology 2001;1:242-5.

127 Khan AA, Ali L. Tropical calcific pancreatitis and FCPD in Bangladesh. J Gastroenterol Hepatol 1997;12(June):S48-52.

128 Mohan V, Snehalatha C, Chari ST, et al. Clinical and biochemical studies in the prediabetic phase of tropical calcific pancreatitis. Pancreas 1992:7:109-13.

129 Yainik CS. Diabetes secondary to Tropical Calcific Pancreatitis. In: Alberti KGMM, Johnston DG, eds. Bailliere's clinical endocrinology and metabolism. London: Saunders, 1992:777-95.

130 Mohan V, Premalatha G, Padma A, et al. Fibrocalculous pancreatic diabetes-long term survival analysis. Diabetes Care 1996;19:1274-8.

131 Owyang C, Louie DS, Tatuma D. Feedback regulation of pancreatic enzyme secretion: suppression of cholycystokinine by release by trypsin. J Clin Invest 1986;77:2042-7

132 Krawisz BR, Miller $\sqcup$, DiMagno EP, et al In the absence of nutrients, pamncreatic biliary secretion in the jejunum do not exert feedback control of human pancreatic or gastric function. J Lab Clin Med 1980;95:13-18.

133 Mossner J, Wresky HP, Kestel W, et al. Influence of treatment with pancreatic enzymes on pancreatic enzyme secretion. Gut 1989;30:1143-9.

134 Slaff J, Jacobson D, Tillman CR, et al. Protease-specific suppression of pancreatic exocrine secretion. Gastroenterology 1984;87:44-52.

135 Braganza JM. A framework for the aetiogenesis of chronic pancreatitis. Digestion 1998;59(suppl 4): 1-12.

136 Halgreen $\mathbf{H}$, Paderson NT, Worning $H$. Symptamatic effect of pancreatic enzyme therapy in patients of chronic pancreatitis. Scand J Gastroenterol 1986;21:104-8.

137 Mossner J, Secknus R, Meyer J, et al. Treatment of pain with pancreatic extracts in chronic pancreatitis: a result of prospective placebo-controlled multicenter trial. Digestion 1992;53:54-66.

138 Malesci A, Gaia E, Fioretta A, et al. No effect of long term treatment with pancreatic extract on abdominal pain in patients with chronic pancreatitis. Scand J Gastroenterol 1995;30:392-8.

139 Tandon RK, Nobuhiro Sato, Garg PK. Chronic pancreatitis: Asia-Pacific consensus report. J Gastrenterol Hepatol 2002;17:508-18.

140 Greenberger NJ. Enzymatic therapy in patients with chronic pancreatitis. Gastroenterol Clin North Am 1999;28:6878-93.

141 Uden S, Bilton D, Nathan L, et al. Antioxidant therapy for recurrent pancreatitis: placebo controlled trial. Aliment Pharmacol Ther $1990 \cdot 4 \cdot 357-71$

142 Choudhury A, Garg PK, Tandon RK. The role of oxidative stress in tropical pancreatitis and effect of antioxidants supplementation on pain in patients with tropical pancreatitis. J Gastroenterol Hepatol 2001;16(suppl):A132.

143 Mohan V, Poongothai S, Pitchumoni CS. Oral pancreatic enzyme in the control of diabetes mellitus in tropical calculous pancreatitis. Int J Pancreatol 1998;24:19.

144 Thomas PG, Augustine P, Ramesh H, et al. Observations and surgical management of tropical pancreatitis in Kerala and southern India. World J Surg 1990:14:32-42.

145 Thomas PG, Augustine P. Surgery in tropical pancreaitits. Br J Surg 1988;75:161-4.

146 Tripathy BB. Epidemiology of tropical calcific pancreatitis. In: Kumar N Acharya SK, eds. Tropical calcific pancreatitis. Trivandrum: Roussel Scientific Institute, 1994:12-28.

147 Varughese M. Surgery in pancreatic diabetes. In: Podolsky S, Viswanathan M, eds. Secondary diabetes: the spectrum of the diabetic syndrome. New York: Raven Press, 1980:231-8.

\section{ANSWERS}

1. D, 2. A, 3. A, 4. C, 5. C, 6. D 